\title{
Práticas Educativas Maternas e Indicadores do Desenvolvimento Social no Terceiro Ano de Vida
}

\author{
Child-Rearing Practices and Social Development Indicators \\ in Three-Year-Old Children
}

\author{
Patrícia Alvarenga ${ }^{*}, a$ \& Cesar Augusto Piccinini ${ }^{b}$ \\ ${ }^{a}$ Universidade Federal da Bahia \& ${ }^{b}$ Universidade Federal do Rio Grande do Sul
}

\begin{abstract}
Resumo
O objetivo deste estudo foi investigar as relações entre as práticas educativas maternas e indicadores dos problemas de externalização e da competência social em crianças aos 30 meses de vida. Participaram do estudo 23 díades mãe-criança. No $30^{\circ}$ mês de vida da criança foi realizada uma observação da interação mãecriança para a avaliação das práticas educativas maternas, dos problemas de externalização e da competência social das crianças. Os resultados apóiam a literatura que relaciona práticas de orientação, controle assertivo e envolvimento parental positivo à competência social, e práticas coercitivas e permissivas aos problemas de externalização. Discute-se a relevância das práticas educativas parentais para a compreensão do desenvolvimento social, enfatizando a importância de práticas menos referidas na literatura, como a autorização de autonomia, a intrusividade e o controle ambíguo.

Palavras-chave: Práticas educativas parentais; competência social; problemas de externalização.
\end{abstract}

\begin{abstract}
The present work aimed at investigating relations between maternal child-rearing practices, externalizing behavior problems and social competence indicators of thirty-month-old children. The study involved 23 child-mother dyads. In the child's thirtieth month after birth, an observation of mother-child interaction was performed in order to evaluate maternal child-rearing practices, externalizing behavior problems and child social competence. The results support the literature about social development that relates child-rearing practices such as guidance, assertive control and positive parental involvement to social competence, and coercive and permissive practices to externalizing behavior problems. The work discusses the relevance of parental child-rearing practices for the comprehension of the social development, emphasizing the importance of child-rearing practices, such as autonomy authorization, intrusiveness and ambiguous control.

Keywords: Child-rearing practices; social competence; externalizing behavior problems.
\end{abstract}

A maioria das teorias sobre o desenvolvimento social prevê uma continuidade entre a relação pais-criança e a qualidade da interação da criança com os pares. Esta noção tem sido sistematicamente endossada por achados empíricos de pesquisas realizadas nas últimas décadas (Hart, Ladd, \& Burleson, 1990; Landry, Smith, Swank, Assel, \& Vellet, 2001). É inicialmente no contato com os pais, que a criança aprende uma série de habilidades que passarão por contínua transformação, em decorrência das exigências e desafios impostos pelo ingresso em novos grupos sociais (Castro, Melo, \& Silvares, 2003).

Entre os indicadores do desenvolvimento social que podem ser avaliados nos primeiros anos de vida, destacam-se aqueles relacionados aos problemas de externalização e à competência social. Os problemas de externalização estão ligados à agressividade, impulsividade, comportamento

${ }^{*}$ Endereço para correspondência: Rua Aristides Novis, 197, Federação, Salvador, BA, Brasil, CEP 40210-730. E-mail: palvarenga66@gmail.com

Agradecemos a colaboração de Airana Fidelis da Luz Moura

e Luciana Ouriques durante a análise dos dados. desafiador e comportamento delinqüente, e têm sido apontados como aqueles que apresentam maior prevalência (Campbell, 1995; Silva, 1999), maior estabilidade ao longo do tempo (Egeland, Kalkoske, Gottesman, \& Erickson, 1990; Pettit, Bates, Dodge, \& Meece, 1999) e maior probabilidade de evoluírem para quadros clínicos mais graves na adolescência e na vida adulta (Pacheco, Alvarenga, Reppold, Piccinini, \& Hutz, 2005; Wangby, Bergman, \& Magnusson, 1999). A competência social refere-se às habilidades de entender normas sociais, interagir com os adultos e com os pares de forma positiva, e regular suas emoções, especialmente as emoções negativas (Kliewer, 1991). A literatura é consensual ao considerar a necessidade e as possibilidades de avaliar indicadores de competência social e dos problemas de externalização nos primeiros anos de vida.

Há evidências de que as primeiras manifestações dos problemas de externalização possam ser detectadas precocemente, aproximadamente entre os 18 e os 24 meses. Nessa idade a criança já teria tendência a agredir os pais ou pares, a destruir objetos e apresentar conduta desafiadora. 
(Crockenberg \& Litman, 1990; Keenan \& Shaw, 1997). Para Landry et al. (2001) a habilidade da criança de engajarse em interações sociais de forma positiva com os pais, incluindo gestos, vocalizações, olhares e demonstrações de afeto positivo, são importantes sinalizadores da competência social, que já podem ser avaliados a partir dos 6 meses de vida. Mais tarde, em torno do segundo ano, a empatia (Hay, 1994), a assertividade (Crockenberg \& Litman, 1990), e a obediência, considerada um importante preditor da cooperação (Kochanska, 2002; Maccoby, 1966), constituem as principais formas de avaliar a competência social nesse período do desenvolvimento.

Patterson, Reid e Dishion (1992) afirmam que o conceito chave para explicar o início do processo de socialização, que ocorre no contexto familiar, é o de contingência das práticas educativas parentais. O conceito de contingência faz referência ao fato de os pais comportarem-se efetiva e consistentemente no sentido de reduzir comportamentos inadequados e coercitivos, e de estimular a ocorrência de comportamentos socialmente adequados. Em um ambiente contingente, a criança, na maior parte do tempo, sabe que comportamentos levarão a conflito e que comportamentos produzem encorajamento e afeto. Além das práticas contingentes, o envolvimento parental, que refere-se a atividades que envolvam trocas positivas entre pais e filhos, constitui um aspecto não contingente da relação que contribuiria significativamente para a competência social e para o desenvolvimento da auto-estima. Por outro lado, práticas parentais não contingentes levariam ao desenvolvimento de um padrão anti-social, caracterizado na primeira infância pelos problemas de externalização. Para Patterson et al. (1992), os membros da família treinam diretamente esses comportamentos na criança. Os pais, em geral, não são contingentes no uso de reforçadores positivos para iniciativas pró-sociais (Dumas \& Wahler, 1985) e fracassam no uso efetivo de técnicas disciplinares para enfraquecer os comportamentos desviantes (DeBaryshe, Patterson, \& Capaldi, 1993). O efeito das práticas parentais ineficazes é permitir uma série de interações diárias, nas quais os membros da família inadvertidamente reforçam o comportamento coercitivo e os problemas de conduta da criança (Capaldi, Chamberlain, \& Patterson, 1997). Em geral, a criança utiliza-se de comportamentos aversivos para interromper a solicitação ou exigência de um outro membro da família. A conseqüência deste tipo de funcionamento familiar é que, na medida em que os comportamentos da criança se agravam, as estratégias de controle dos pais tornam-se progressivamente mais coercitivas e severas, embora ineficazes (Patterson, DeGarmo, \& Knutson, 2000).

Seguindo esta perspectiva, vários estudos têm investigado o papel das práticas educativas parentais no desenvolvimento da competência social e dos problemas de externalização. A maioria dos estudos que investiga as relações entre a competência social e as práticas educativas parentais confirma a importância do uso de práticas não-coercitivas no geral (explicações, sugestões), do reforçamento positivo contingente e do envolvimento positivo dos pais com a criança (Arsenio \& Overton, 2004). Crockenberg e Littman
(1990) investigaram a relação entre as práticas educativas maternas e a assertividade de crianças com 2 anos de idade. Foram encontradas correlações positivas da assertividade com o uso de comandos diretos, do reforçamento contingente e com o uso de orientações e sugestões. No estudo de Dumas e LaFreniere (1993), constatou-se que mães de crianças consideradas socialmente competentes foram mais positivas em suas interações com os filhos (demonstrações de aprovação, palavras e gestos de carinho, etc.) e menos coercitivas (críticas, punições, desaprovação, intrusividade), quando comparadas às mães de crianças consideradas ansiosas ou agressivas, durante a interação em uma tarefa estruturada. Cabe destacar aqui o conceito de intrusividade materna. A intrusividade pode ser definida como uma tendência ao controle exagerado dos comportamentos da criança, que demonstra pouca sensibilidade a sua necessidade crescente de autonomia. Mães intrusivas costumam monitorar cada passo da criança, reagindo com perguntas, comentários ou repreensões freqüentes (Oliveira, Frizzo, \& Marin, 2000). A conduta intrusiva dos pais estaria relacionada aos problemas de externalização, enquanto a autorização de autonomia estaria relacionada ao desenvolvimento da competência social.

Com relação aos problemas de externalização, percebese um claro consenso na literatura quanto à noção de que eles estão relacionados ao uso predominante de práticas de caráter coercitivo (Ferreira \& Marturano, 2002; Pettit et al., 1999). No estudo de McLoyd e Smith (2002), o uso de punição física esteve associado a um aumento dos problemas de externalização em crianças que foram acompanhadas dos 4 aos 10 anos de idade, sendo que o afeto e o suporte emocional fornecidos pela mãe foram moderadores nessa relação. Apoiando esses achados, o estudo Alvarenga e Piccinini (2001) demonstrou que as práticas de caráter coercitivo foram relatadas com maior frequiência por mães de crianças que apresentavam problemas de externalização, em comparação com mães de crianças sem problemas de comportamento. Além do uso demasiado da coerção, pais de crianças com problemas de externalização costumam ser pouco assertivos, mais intrusivos e permissivos. Isto inclui reforçar positivamente comportamentos inadequados ou utilizar pouco o reforçamento positivo para aspectos adequados da conduta dos filhos, assim como dar ordens confusas ou ambíguas à criança e ignorar ou reforçar comportamentos agressivos e desafiadores (Patterson et al., 1992).

Por outro lado, o estudo de Crockenberg e Littman (1990) encontrou, além da relação com as práticas coercitivas (críticas, ameaças e punições físicas), ligações entre o uso de comandos diretos (ordens e pedidos) e o comportamento desafiador em crianças de 2 anos de idade. Existem outras evidências de que o uso de estratégias de controle moderadas como os comandos diretos, por exemplo, poderiam estar associadas também ao comportamento desafiador (Belsky, Woodworth, \& Crnic, 1996; Kuczynski, Kochanska, RadkeYarrow, \& Girnius-Brown, 1987). Esses achados sugerem a importância de que seja considerado o uso de estratégias combinadas. É possível levantar a hipótese de que o uso 
predominante ou muito freqüente de práticas coercitivas, especialmente de modo não contingente, esteja associado aos problemas de externalização, enquanto o uso moderado e contingente da coerção, combinado com estratégias de controle assertivo esteja ligado ao desenvolvimento da competência social e à ausência de problemas de conduta.

Assim o presente estudo investigou a relação entre as práticas educativas maternas, a competência social e os problemas de externalização de crianças, privilegiando não apenas o aspecto da presença ou ausência de coerção, mas também características como a intrusividade, a permissividade, formas ambíguas de controle e a autorização de autonomia (sensibilidade).

\section{Método}

\section{Participantes}

Participaram deste estudo 23 díades mãe-criança de diferentes níveis socioeconômicos, com 13 meninos e 10 meninas, que tinham 30 meses de idade. As crianças eram saudáveis e nascidas a termo. Todas as mães eram primíparas, com idade média de 24,39 anos $(D P=5,88)$ e residiam com seus maridos ou companheiros na região metropolitana de Porto Alegre. Nenhuma delas relatou complicações durante a gestação.

A amostra foi selecionada, com base nos critérios descritos acima, dentre os participantes do "Estudo Longitudinal de Porto Alegre: Da Gestação à Escola” (Piccinini, Tudge, Lopes, \& Sperb, 1998), que iniciou acompanhando 81 gestantes, que não apresentavam intercorrências clínicas, com elas mesmas ou com o bebê, que era seu primeiro filho. Detalhes sobre os participantes deste estudo são descritos no trabalho de Alvarenga e Piccinini (2007). Afora os dados sociodemográficos coletados na gestação, o presente estudo considerou apenas dados obtidos na Fase 7 de coleta de dados do estudo longitudinal, quando a criança estava com 30 meses de idade. Dentre as famílias participantes, 10 foram selecionadas em hospitais, 2 em postos de saúde, 6 por indicação e 5 através de divulgação em jornal.

\section{Procedimentos e Instrumentos}

Seguindo o delineamento do Estudo Longitudinal, quando as crianças completavam 30 meses de vida as famílias eram visitadas em suas residências para a realização da Observação da interação familiar $-30^{\circ}$ mês (Grupo de Interação Social, Desenvolvimento e Psicopatologia [GIDEP], 2001), que envolveu a filmagem de um almoço familiar, utilizada para a avaliação das práticas educativas maternas e dos indicadores de problemas de externalização e de competência social nas crianças. O contexto de alimentação foi escolhido por ser referido na literatura como um tipo de situação durante o qual oportunidades de as mães regularem o comportamento das crianças de práticas educativas seriam freqüentes (Crockenberg \& Litman, 1990). $\mathrm{O}$ pai da criança estava presente durante a filmagem em 20 dos 23 casos analisados, e outros membros da família como avós ou tios, estiveram presentes em sete casos. Para
Tabela 1

\section{Características Demográficas dos Participantes $(N=23)$}

\begin{tabular}{ll}
\hline Sexo da criança & $10(43,5 \%)$ \\
Feminino & $13(56,5 \%)$ \\
Masculino & $M=24,39(D P=5,88)$ \\
Idade da mãe no momento da gestação & $M=27,57(D P=7,22)$ \\
Idade do pai no momento da gestação & \\
Escolaridade da mãe & $1(4,3 \%)$ \\
Ensino fundamental incompleto & $3(13 \%)$ \\
Ensino fundamental completo & $3(13 \%)$ \\
Ensino médio incompleto & $8(34,8 \%)$ \\
Ensino médio completo & $5(21,7 \%)$ \\
Ensino superior incompleto & $3(13 \%)$ \\
Ensino superior completo & \\
Escolaridade do pai & $5(21,7 \%)$ \\
Ensino fundamental incompleto & $1(4,3 \%)$ \\
Ensino fundamental completo & $2(8,7 \%)$ \\
Ensino médio incompleto & $7(30,4 \%)$ \\
Ensino médio completo & $2(8,7 \%)$ \\
Ensino superior incompleto & $5(21,7 \%)$ \\
Ensino superior completo & $1(4,3 \%)$ \\
Pós-graduação & \\
Estado civil da mãe & $16(69,6 \%)$ \\
Casada & $7(30,4 \%)$ \\
União estável &
\end{tabular}

fins de análise foram considerados apenas os momentos de interação da mãe com a criança durante o almoço, durante 12 minutos, a partir do momento em que a criança sentava-se à mesa. Os 12 minutos selecionados foram divididos em 24 intervalos de 30 segundos durante os quais foram codificadas as práticas educativas da mãe e os comportamentos da criança. A estrutura de categorias utilizada para a análise da interação foi elaborada com base nos trabalhos de diversos autores (Crockenberg \& Litman, 1990; Eddy, Leve \& Fagot, 2001; Landry et al., 2001; Paley, Cox, \& Kanoy, 2001; Patterson et al., 1992). As práticas educativas maternas foram codificadas em oito categorias distintas: (a) Orientação: tentativas da mãe de regular o comportamento da criança de forma pouco intrusiva. Inclui perguntar se a criança precisa de ajuda, persuadir ou explicar alguma situação, ou negociar algum aspecto com a criança. Foi registrada também quando um comando era acompanhado de argumento ou explicação. Exemplos: Quando a criança pede água a mãe pergunta se ela não prefere tomar o suco, que já está servido (persuasão); "Eu vou colocar [no prato] só o que você vai comer"; "Isso não é polenta, é purê de batata"; "Quer comer um pouco no colo da mãe?"; "Te dou mais batata depois que você comer o papá"; "Não tem refrigerante. Só tem água ou suco e você não gosta de suco". (b) Sensibilidade: manifestações maternas que indicam atenção, consideração e respeito em relação às necessidades, desejos ou vontades da criança, quando estes são manifestados de forma assertiva pela criança. Observa-se quando a mãe concorda ou atende um pedido da criança ou aceita sua recusa diante de um co- 
mando. Incluem-se também nessa categoria perguntas da mãe sobre necessidades, desejos, preferências ou opiniões da criança, que demonstram curiosidade ou interesse. Exemplos: Mãe deixa a criança se alimentar sozinha quando ela faz uma tentativa de levar a colher à boca; "Você quer feijão?”; “Tá bom filha?”; "Você tá com sono?”; "Tá com fome?"; "Você gosta de sopa, né?". (c) Envolvimento positivo: manifestações de afeto e apoio em relação à criança através de comportamentos não-verbais (carícias, entusiasmo, sorrisos) e verbais (elogios e comentários espontâneos e entusiasmados sobre a atividade da criança). Incluem-se também nessa categoria perguntas, respostas e relatos da mãe quando ela conversa com a criança sobre outros temas não relacionados à refeição. Não foram incluídos nessa categoria elogios oferecidos contingentemente após a criança atender um comando materno. Quando a mãe conversava com o pai sobre a criança a categoria não foi registrada. Exemplos: "É uma filmadora [mãe referindo-se a câmera]"; "Que bom que você vai comer tudo isso!"; "Pra quem você tá atirando beijos?"; "Você tá dançando?"; "Você sabe o que eu vi ontem? Um monte de cavalos". (d) Controle assertivo: comportamentos maternos assertivos, incluindo comandos, ordens ou proibições diretas, claras e precisas, feitas à criança de forma não coercitiva. $\mathrm{O}$ tom de voz da mãe deveria revelar firmeza e assertividade. Também foram classificadas nessa categoria recompensas ou reforços (elogios, comentários estimulantes que indicam aprovação ou entusiasmo) oferecidos contingentemente após a criança atender um comando materno. Exemplos: "Agora come tudo"; "Já tá limpo [ao ver a criança limpando insistentemente a boca no guardanapo]"; "Não faz assim filha. Come com a colher"; "Não põe a mãozinha”. (e) Controle ambíguo: refere-se a formas indiretas e ambíguas de exercer controle, utilizadas pela mãe. Incluem-se nessa categoria ordens, pedidos, proibições e sugestões vagas, indiretas ou confusas e comandos em forma de pergunta. $\mathrm{O}$ tom hesitante ou excessivamente polido de voz da mãe ao dar o comando ou ordem indica a presença de controle ambíguo. Exemplos: "Ah filho, tu sempre come, agora não quer comer [em tom de desapontamento ou apelo]"; A criança diz "Agora chega" e a mãe diz "Como agora chega?"; "Não quer batata? [em tom de surpresa]"; "Vai botar tudo na boca?". (f) Controle coercitivo: comportamentos da mãe que têm por objetivo regular ou controlar o comportamento da criança de forma coercitiva. O controle coercitivo verbal envolve repreensões, ameaças, verbalizações hostis, queixas, críticas, provocações ou comentários depreciativos em relação ao comportamento da criança. Comandos, ordens, pedidos ou proibições feitos à criança de forma hostil também foram codificados nessa categoria. O controle coercitivo nãoverbal envolve o uso de qualquer tipo de restrição física (tirar objeto da mão da criança), castigo ou punição física. Exemplos: mãe tira a mamadeira com suco das mãos da criança; mãe busca um cinto e coloca em uma cadeira ao seu lado; mãe diz "senta aî" ao mesmo tempo em que segura a criança na cadeira; "Eu vou comer a tua comida, tô tirando tudo do teu prato"; "Come senão tu não vai sair depois"; "Eu vou dar o teu skate pro vizinho"; "Se tu não vem papar a tia vai embora". (g) Intrusividade: manifestações da mãe que indicam que ela não percebe ou simplesmente não responde às necessidades de autonomia da criança ou a seus desejos e pontos de vista. Exemplos: mãe insiste em levar a colher com alimento à boca da criança mesmo que ela mostre sinais de recusa; mãe tira a colher da mão da criança quando ela está se alimentando sozinha e começa a lhe dar a comida na boca; mãe faz pergunta e responde pela criança; criança pedindo para sair da mesa e mãe diz: “Quer mais guaraná?”. (h) Permissividade: envolve o reforçamento ou incentivo para comportamentos inadequados ou negligência diante de comportamentos agressivos da criança. Incluem-se nessa categoria frases que distraem a criança ou mudam o foco da interação sem comentar diretamente o comportamento inadequado. Comportamentos não-verbais como riso ou concordância diante de comportamentos inadequados da criança que não tenham caráter agressivo ou desafiador também foram registradas nessa categoria, assim como ocasiões em que a mãe ignora comportamentos inadequados da criança que tenham caráter agressivo ou desafiador, demonstrando um nível excessivo de tolerância. Exemplo: Mãe ri quando a filha choraminga pedindo que ela tire a salada do seu prato, ao mesmo tempo em que atende o pedido da criança; criança joga o garfo contra a mãe, e a mãe apenas recoloca o garfo sobre a mesa. As categorias de orientação, sensibilidade, envolvimento positivo e controle assertivo foram agrupadas e denominadas práticas educativas facilitadoras do desenvolvimento social. As categorias de controle ambíguo, controle coercitivo, intrusividade e permissividade foram agrupadas como práticas educativas não-facilitadoras do desenvolvimento social. Os comportamentos da criança foram avaliados através de seis categorias distintas: (a) Obediência: essa categoria refere-se a comportamentos da criança relacionados a um comando ou pedido da mãe, que são congruentes com seu comando ou pedido. Exemplo: Criança tira a mão do prato quando a mãe lhe diz para fazê-lo. Quando a criança estava se alimentando sozinha sem que a mãe tivesse lhe dado algum comando específico o comportamento não foi registrado. (b) Assertividade: comportamentos que manifestam de forma assertiva os desejos, vontades ou pontos de vista da criança ou indicam que ela não quer cooperar ou atender um comando, ordem, pedido ou sugestão da mãe, sem demonstrar hostilidade, comportamento agressivo ou desafiador. Por exemplo, a criança diz o que deseja fazer ou responde dizendo "não" ou "eu não quero" a um comando, pedido ou sugestão materna, ou ainda quando a criança tenta negociar com a mãe o comando ou pedido em questão. Exemplos: Criança manifesta negação movimentando a cabeça quando a mãe pergunta se ela quer mais arroz; criança responde "não" quando a mãe lhe pergunta se a comida está boa; "Bota polenta, bota salada, bota carne"; "Isso tá estragado"; "Quero água"; "Depois eu quero comer batata". (c) Envolvimento positivo: comportamentos que indicam expressão de afeto positivo da criança em relação à mãe como sorrisos, carícias, e demonstrações de entusiasmo através de comen- 
tários ou elogios. Incluem-se também nessa categoria perguntas, respostas e relatos da criança quando ela conversa com a mãe sobre outros temas não relacionados à refeição. Exemplos: Criança atira beijos para a mãe; criança pergunta à mãe sobre a filmadora; mãe diz para a criança: "Come pra ficar bem forte" e a criança fala: "E bem grande também!”. (d) Inadequação: comportamentos inadequados ou inconvenientes da criança que não apresentam caráter agressivo ou desafiador, como chorar, choramingar ou fingir que está chorando (desde que não esteja com dor ou machucado), gritar ou usar tom de voz irritante para falar, dizer palavrões (não dirigidos a alguém), reclamar, teimar (insistir em algum pedido de forma inconveniente ou irritante), interromper a mãe quando ela está falando ou apresentar atividade motora excessiva. Se a criança estivesse brincando na mesa sem estar perturbando, essa categoria não era registrada. Exemplos: A criança pede choramingando a sua mãe que ela tire a salada do seu prato; criança fica com a boca aberta mostrando a comida que está mastigando; criança torce a blusa insistentemente amassando o tecido; criança pega o copo que a mãe havia colocado fora de seu alcance, dizendo que ele só poderia tomar após a refeição; "Eu vou fugir de ti"; "Eu quero ver televisão [insistindo em tom de voz irritante]". (e) Desobediência passiva: essa categoria refere-se a comportamentos da criança de ignorar comandos, pedidos ou perguntas da mãe, não apresentando nenhum tipo de resposta durante o intervalo. Exemplo: Mãe pergunta se a criança quer feijão e ela não apresenta nenhum tipo de resposta; mãe diz para a criança não colocar a mão na comida e ela continua a colocar. (f) Negativismo: inclui fazer o oposto do que a mãe solicita, intensificar um comportamento que a mãe pede que a criança interrompa, ameaçar ou provocar a mãe ou expressar raiva ou agressividade em resposta a um pedido ou ordem materna. Inclui também comportamentos agressivos dirigidos à mãe como bater, morder, chutar ou empurrar, destruir ou jogar objetos, bem como verbalizações agressivas da criança como, por exemplo, dizer palavrões (dirigidos à mãe ou a outra pessoa) ou xingar alguém. Exemplos: Criança joga a colher no chão; criança coloca a mão na comida e a mãe diz para não fazer isso, mas a criança intensifica o comportamento. As categorias obediência, assertividade e envolvimento positivo foram agrupadas como indicadores de competência social e as categorias inadequação, desobediência passiva e negativismo foram agrupadas como indicadores de problemas de externalização. Apesar de ser referida na literatura como um componente relevante da competência social, a empatia não foi incluída como uma categoria de comportamento infantil porque comportamentos indicadores de empatia não ocorreram durante a situação filmada. Isto ocorreu possivelmente devido ao tipo de contexto escolhido para a observação, que propiciou a observação de outras dimensões da competência social, porém, não possibilitou a avaliação da empatia. A codificação dos vídeos foi realizada por dois codificadores independentes, extensamente treinados e a fidedignidade foi estabelecida em 10 vídeos. Para as oito categorias de práticas educativas o valor de Kappa variou de $K=0,66$ a $K=0,93(M=0,85)$. Para as seis categorias de comportamentos infantis, o coeficiente variou de $K=0,74$ a $K=0,93(M=0,85)$.

\section{Resultados}

Para examinar as relações entre as práticas educativas materna e os indicadores de competência social e problemas de externalização no $30^{\circ}$ mês de vida da criança, inicialmente foi realizado o Teste de Correlação de Spearman utilizando-se as frequiências médias das categorias analisadas. A Tabela 2 apresenta estes resultados. Os resultados revelaram correlações positivas entre o total de práticas facilitadoras e as categorias de comportamento infantil obediência $(\mathrm{r}=0,69 ; p<0,01)$, e assertividade $(\mathrm{r}=0,47$; $p<0,05)$. A obediência correlacionou-se positivamente com orientação $(\mathrm{r}=0,44 ; p<0,05)$, sensibilidade $(\mathrm{r}=0,50$; $p<0,05)$ e controle assertivo $(\mathrm{r}=0,78 ; p<0,01)$. Foram encontradas também duas correlações positivas envolvendo a assertividade e as categorias de práticas orientação ( $\mathrm{r}=0,47$; $p<0,05)$ e sensibilidade $(\mathrm{r}=0,43 ; p<0,05)$. $\mathrm{O}$ envolvimento positivo infantil esteve positivamente correlacionado com o envolvimento positivo da mãe $(\mathrm{r}=0,80 ; p<0,01)$. Por fim, também foram verificadas correlações positivas entre o total de indicadores de competência social e as categorias orientação $(\mathrm{r}=0,43 ; p<0,05)$ e envolvimento positivo $(\mathrm{r}=0,54 ; p<0,01)$. Todos esses achados apóiam a expectativa inicial de que as práticas educativas facilitadoras estariam associadas aos indicadores de competência social.

No entanto, a obediência correlacionou-se positivamente com o controle coercitivo $(\mathrm{r}=0,47 ; p<0,05)$, e com o total de práticas não-facilitadoras $(\mathrm{r}=0,53 ; \mathrm{p}<0,01)$. Estes resultados sugerem que a obediência, ao contrário dos outros indicadores de competência social avaliados nesse estudo, pode também estar relacionada ao uso de práticas de caráter coercitivo.

Quanto às relações encontradas entre as práticas nãofacilitadoras e os indicadores de problemas de externalização, foram encontradas também correlações positivas entre o total de práticas não-facilitadoras e as categorias inadequação $(\mathrm{r}=0,45 ; p<0,05)$ e desobediência passiva $(\mathrm{r}=0,41 ; p<0,05)$. A análise das relações entre as categorias específicas de práticas não-facilitadoras e os indicadores de problemas de externalização revelou uma correlação positiva entre a inadequação e o controle ambíguo $(\mathrm{r}=0,51 ; p<0,05)$. Também foi verificada uma correlação positiva entre o total de indicadores de problemas de externalização e o controle coercitivo $(\mathrm{r}=0,44 ; p<0,05)$. Todos esses achados apóiam a expectativa inicial de que as práticas educativas não-facilitadoras estariam associadas aos indicadores de problemas de externalização.

Contudo, ocorreram também correlações positivas entre certas categorias de práticas facilitadoras e indicadores dos problemas de externalização. Por exemplo, a desobediência passiva correlacionou-se positivamente com o controle assertivo $(\mathrm{r}=0,62 ; p<0,01)$. Além disso, foram constatadas correlações positivas entre o total de indicadores de problemas de externalização e as categorias de práticas faci- 
litadoras orientação $(\mathrm{r}=0,42 ; p<0,05)$, e controle assertivo $(\mathrm{r}=0,46 ; p<0,05)$. Por fim, o total de práticas facilitadoras correlacionou-se positivamente com o total de indicadores de competência social $(\mathrm{r}=0,68 ; p<0,01)$, e o total de práticas não-facilitadoras correlacionou-se com o total de indicadores de problemas de externalização $(\mathrm{r}=0,42 ; p<0,05)$.

Tabela 2

Correlações entre as Práticas Educativas Maternas e os Indicadores de Competência Social e de Problemas de Externalização $(N=23)$

Comportamento infantil

\begin{tabular}{|c|c|c|c|c|c|c|c|c|c|}
\hline Práticas educativas & 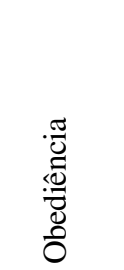 & $\begin{array}{l}\frac{0}{0} \\
\frac{0}{0} \\
.2 \\
0 \\
0 \\
0 \\
0\end{array}$ & 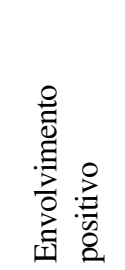 & 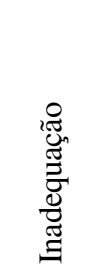 & 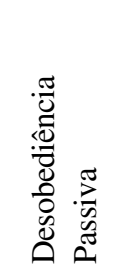 & 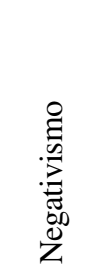 & 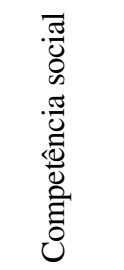 & 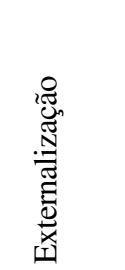 & 氶 \\
\hline \multicolumn{10}{|l|}{ Práticas facilitadoras } \\
\hline Orientação & $0,44 *$ & $0,47 *$ & 0,00 & 0,39 & 0,22 & 0,31 & $0,43 *$ & $0,42 *$ & $0,65 * *$ \\
\hline Sensibilidade & $0,50 *$ & $0,43^{*}$ & $-0,19$ & $-0,13$ & 0,08 & $-0,22$ & 0,38 & $-0,06$ & 0,34 \\
\hline Envolvimento positivo & 0,04 & $-0,03$ & $0,80 * *$ & 0,20 & $-0,09$ & 0,04 & $0,54 * *$ & 0,06 & 0,36 \\
\hline Controle assertivo & $0,78 * *$ & 0,21 & $-0,04$ & 0,29 & $0,62 * *$ & $-0,22$ & 0,41 & $0,46^{*}$ & $0,58 * *$ \\
\hline \multicolumn{10}{|l|}{ Práticas não-facilitadoras } \\
\hline Controle ambíguo & 0,37 & $-0,20$ & $-0,13$ & $0,51 *$ & 0,23 & $-0,20$ & $-0,05$ & 0,41 & 0,24 \\
\hline Controle coercitivo & $0,47 *$ & $-0,01$ & 0,06 & 0,38 & 0,36 & $-0,04$ & 0,20 & $0,44 *$ & 0,38 \\
\hline Intrusividade & 0,29 & $-0,04$ & $-0,37$ & 0,27 & 0,28 & $-0,11$ & $-0,16$ & 0,07 & 0,25 \\
\hline Permissividade & 0,29 & $-0,03$ & $-0,35$ & 0,28 & 0,35 & $-0,08$ & $-0,11$ & 0,35 & 0,22 \\
\hline Total práticas facilitadoras & $0,69 * *$ & $0,47 *$ & 0,16 & 0,17 & 0,23 & $-0,00$ & $0,68 * *$ & 0,23 & $0,71 * *$ \\
\hline Total práticas não-facilitadoras & $0,53 * *$ & $-0,02$ & $-0,02$ & $0,45^{*}$ & $0,41^{*}$ & $-0,08$ & 0,17 & $0,42 *$ & $0,50 *$ \\
\hline Total de práticas maternas & $0,75^{* *}$ & 0,38 & 0,16 & 0,33 & 0,31 & $-0,03$ & $0,65 * *$ & $0,74 * *$ & 0,36 \\
\hline
\end{tabular}

Nota. $* p<0,05, * * p<0,01$.

Em uma segunda etapa, foi realizada uma análise de regressão linear múltipla dos escores totais de indicadores de competência social sobre as práticas facilitadoras. De acordo com os resultados o modelo de regressão múltipla, considerando os quatro fatores analisados, explica 36\% (R2 total ajustado $=0,36$ ) da variância total da competência social das crianças. Para cada ocorrência a mais da categoria envolvimento positivo a freqüência total de competência social aumentou em 0,77. A Tabela 3 apresenta os dados da análise de regressão.

Tabela 3

Análise de Regressão Múltipla da Freqüência Total de Indicadores de Competência Social da Criança sobre as Práticas Facilitadoras $(N=23)$

\begin{tabular}{lccl}
\hline Fatores preditores & B & SE Beta & $p(\mathrm{~T})$ \\
\hline Orientação & 0,23 & 0,14 & 0,46 \\
Sensibilidade & 0,36 & 0,20 & 0,32 \\
Envolvimento positivo & 0,77 & 0,44 & 0,01 \\
Controle assertivo & 0,65 & 0,30 & 0,14 \\
\hline
\end{tabular}

Nota. $F=4,19 ; p=0,01$.

O mesmo procedimento estatístico foi realizado para verificar o impacto das práticas educativas não-facilita- doras nos indicadores de problemas de externalização. De acordo com os resultados o modelo de regressão múltipla, considerando os quatro fatores analisados, explica 56\% $(R 2$ total ajustado $=0,56)$ da variância total dos problemas de externalização das crianças. Para cada ocorrência a mais da categoria controle coercitivo a frequiência total de problemas de externalização da criança aumentou em 0,77, e para cada ocorrência a mais de permissividade a freqüência total de problemas de externalização da criança aumentou em 4,38. A Tabela 4 apresenta os dados da análise de regressão.

Tabela 4

Análise de Regressão Múltipla da Freqüência Total de Indicadores de Problemas de Externalização da Criança sobre as Práticas Não-Facilitadoras $(N=23)$

\begin{tabular}{lccc}
\hline Fatores preditores & $\mathrm{B}$ & $\mathrm{SE}$ Beta & $p(\mathrm{~T})$ \\
\hline Controle ambíguo & 0,74 & 0,21 & 0,35 \\
Controle coercitivo & 0,77 & 0,54 & 0,02 \\
Intrusividade & $-5,79$ & $-0,44$ & 0,06 \\
Permissividade & 4,38 & 0,72 & 0,01 \\
\hline
\end{tabular}

Nota. $F=8,18 ; p=0,01$. 


\section{Discussão}

Os resultados apresentam várias evidências das relações entre as práticas facilitadoras e a competência social, bem como entre as práticas não-facilitadoras e os problemas de externalização. No entanto, também foram encontradas algumas relações entre categorias específicas de práticas facilitadoras e os problemas de externalização e entre certas categorias de práticas não-facilitadoras e a competência social, que serão discutidas a seguir.

As análises preliminares revelaram que as práticas facilitadoras, de modo geral, estiveram relacionadas a todos os indicadores de competência social. Esses resultados estão de acordo com os pressupostos de Patterson et al. (1992), que relacionam positivamente o uso de práticas reforçadoras, assertivas e contingentes ao desenvolvimento social na infância. Destacam-se também as relações encontradas entre a assertividade infantil e a orientação e a sensibilidade da mãe. Esse achado apoia a noção de que o comportamento assertivo da criança é estimulado por atitudes maternas de autorização da autonomia - sensibilidade - e pelo uso de estratégias de controle moderado, como dar explicações ou persuadir a criança - orientação (Crockenberg \& Littman, 1990; Denham, Renwick, \& Holt, 1991). Agindo desta forma diante de demonstrações de assertividade da criança, a mãe estaria reforçando esse padrão comportamental e sinalizando para a criança que sua autonomia e iniciativa são desejáveis e, portanto, acolhidas e respeitadas no contexto familiar.

$\mathrm{O}$ envolvimento positivo da criança também esteve particularmente relacionado ao envolvimento positivo materno. O estudo de McLoyd e Smith (2002) revelou que o afeto e o suporte emocional fornecidos pela mãe são fatores protetivos contra o surgimento de problemas de comportamento em geral. No presente estudo, as demonstrações de afeto e entusiasmo da mãe durante a interação estiveram relacionadas a manifestações semelhantes por parte da criança. Os resultados da análise de regressão da competência social sobre as categorias específicas de práticas facilitadoras confirmaram a importância do envolvimento positivo, que nesta etapa da análise, foi o único fator significativo para explicar a variância na competência social.

Por fim, a obediência infantil esteve relacionada com a orientação, a sensibilidade e o controle assertivo, bem como com as práticas não-facilitadoras, entre elas, o controle coercitivo. Para Crockenberg e Littman (1990), a disponibilidade da criança para obedecer também é afetada pelo grau de autonomia que a mãe permite a ela. Nesse sentindo, a criança estaria mais propensa a cooperar quando ela percebe que participa de uma relação em que há reciprocidade. Quando o controle assertivo é combinado com a sensibilidade e a orientação, a criança, ao mesmo tempo em que sabe o que é esperado dela, sente-se convidada a compartilhar da decisão, expressando seu ponto de vista e compreendendo a situação, o que a torna mais propensa a cooperar.

Os resultados sugerem também que a obediência, ao contrário dos outros indicadores de competência social ava- liados nesse estudo, possa eventualmente ser estimulada por práticas de caráter coercitivo. A literatura revisada indicou achados semelhantes. Para Kochanska (2002), a obediência pode se manifestar na infância de diferentes formas. A criança pode revelar afeto positivo e comprometimento ao obedecer (obediência comprometida), ou pode demonstrar hostilidade ou afeto neutro (obediência situacional). É possível que estas diferentes manifestações da obediência estejam relacionadas a diferentes estratégias reguladoras por parte dos pais. Enquanto a obediência comprometida estaria relacionada a práticas de controle mais fraco ou moderado (ex. sugestões e orientações), a obediência situacional estaria relacionada a estratégias de controle coercitivo, porém, contingente. Como no presente estudo os componentes afetivos da obediência da criança não foram analisados, é possível que ambos os tipos tenham ocorrido, em resposta a diferentes práticas educativas maternas (facilitadoras e não-facilitadoras). A ausência de dados a respeito dos componentes afetivos da obediência deve ser considerada como uma das limitações do presente estudo.

Quanto às relações entre as práticas não-facilitadoras e os problemas de externalização os achados também estão de acordo com as tendências apontadas pela literatura e corroboram o modelo de Patterson et al. (1992). Foi encontrada uma relação entre inadequação e controle ambíguo. O conceito de inadequação foi utilizado no presente estudo para referir comportamentos inconvenientes da criança que não apresentam caráter agressivo ou desafiador, como choramingar, gritar ou usar tom de voz irritante para falar, entre outros. Embora esses comportamentos não apresentem caráter agressivo ou desafiador, quando são eficazes no sentido de produzir gratificações ou interromper exigências do ambiente, podem tornar-se mais freqüentes e gradualmente mais intensos. O controle ambíguo, por sua vez, designa um conjunto de práticas não contingentes que, no entanto, não apresentam um caráter propriamente coercitivo, severo ou necessariamente negligente. $\mathrm{O}$ conceito envolve estratégias maternas como ordens, pedidos, proibições e sugestões que são vagas, indiretas ou confusas. É possível, portanto, que a relação encontrada entre inadequação e controle ambíguo esteja indicando instâncias iniciais do ciclo coercitivo descrito por Patterson et al. (1992). Por exemplo, a criança apresenta comportamentos inconvenientes e diante de tais comportamentos perturbadores, a mãe pede que a criança pare de se comportar daquela forma, embora o faça em um tom apelativo ou hesitante. Esse tipo de estratégia não é eficaz para regular a conduta da criança, ao mesmo tempo em que pode reforçála, caso a criança esteja em busca de atenção. Caso esse padrão de interação se torne freqüente, as condutas inadequadas da criança tenderão a se intensificar e as práticas maternas poderão tornar-se progressivamente mais severas, em função do agravamento crescente do comportamento da criança e da inabilidade da mãe de utilizar práticas mais assertivas e contingentes na regulação da sua conduta.

Embora tenham sido encontradas várias evidências das relações entre as práticas não-facilitadoras e os problemas 
de externalização, ao contrário do que era esperado, também foram encontradas correlações positivas entre esses indicadores e a orientação e o controle assertivo. Além disso, a desobediência passiva esteve particularmente relacionada com o controle assertivo. Existem outras evidências na literatura de que o uso de estratégias de controle moderado poderia estar associado ao comportamento desafiador (Belsky et al., 1996; Kuczynski et al., 1987). Crockenberg e Littman (1990) afirmam que a compreensão desta relação envolve a análise do contexto mais amplo em que o comportamento da criança ocorre. De acordo com as autoras, o comportamento desafiador da criança fica relacionado ao uso de comandos ou outras estratégias maternas assertivas de controle quando estas ocorrem após uma recusa assertiva da criança (ex. dizer não a uma solicitação materna). Por exemplo, a mãe insiste em um comando direto, mesmo após a criança ter manifestado assertivamente a sua recusa em comportar-se da forma solicitada. Nesse contexto, a criança estaria menos propensa a obedecer ou cooperar e mais propensa a demonstrar comportamento desafiador, porque a mãe estaria sinalizando sua não disponibilidade para negociar, explicar a situação ou compreender o ponto de vista da criança. Se a criança obedecesse nesse contexto, estaria de certa forma, abrindo mão de sua autonomia em favor do poder da mãe. Assim, é provável que nesse tipo de situação ela opte por repetir a recusa, ignorar a solicitação da mãe (desobediência passiva) ou desafiá-la. Quanto à relação encontrada entre orientação e os indicadores de externalização, o mesmo tipo de análise é pertinente. Além disso, alguns autores referem que o uso da orientação não associado ao uso de estratégias de controle assertivo (ex. comandos) não seria eficaz na regulação da conduta infantil (Baumrind, 1971; Crockenberg \& Littman, 1990). Isto ocorre porque a criança, ao receber apenas ou predominantemente sugestões e explicações não acompanhadas por comandos mais diretos, não percebe nem atribui poder aos pais. Na ausência de uma expressão clara e assertiva do desejo dos pais, a criança se sentiria livre para cooperar ou não, o que explicaria a relação entre os dois fatores em questão.

Os resultados da análise de regressão dos problemas de externalização social sobre as categorias de práticas nãofacilitadoras confirmaram a importância do controle coercitivo, e destacaram o papel da permissividade, que nesta etapa da análise, mostrou-se um fator muito significativo para explicar a variância nos problemas de externalização. Neste estudo, a permissividade materna foi definida como reforçamento ou incentivo para comportamentos inadequados e negligência diante de comportamentos agressivos ou desafiadores da criança, demonstrando um nível excessivo de tolerância. Segundo Simons, Simons e Wallace (2004) muitos pais adotam uma conduta permissiva por não suportarem a frustração e a raiva dos filhos diante de regras e limites. Ao serem expostos a intensas reações de frustração da criança, quando esta é confrontada com uma regra ou reprovação, os pais podem passar a evitar esse tipo de situação relaxando a disciplina e até mesmo incentivando comportamentos inadequados através de risos e comentá- rios. Como conseqüência, esses comportamentos da criança tendem a tornar-se mais freqüentes e intensos.

Em resumo, os achados deste estudo sobre as relações entre as práticas educativas maternas, a competência social e os problemas de externalização apóiam em grande parte a literatura. Além das práticas coercitivas, que têm recebido maior destaque no que se refere à compreensão da externalização, a relevância de outras práticas descritas como não contingentes, como o envolvimento positivo e a permissividade, mostraram-se relevantes. Além disso, a explicação de ambos os padrões de comportamento infantil parece envolver a consideração do uso de estratégias combinadas, em especial, na fase de desenvolvimento que foi investigada, em que as manifestações de assertividade e autonomia da criança começam a surgir de forma mais definida.

\section{Referências}

Alvarenga, P., \& Piccinini, C. A. (2001). Práticas educativas maternas e problemas de comportamento em pré-escolares. Psicologia: Reflexão e Crítica, 14(3), 449-459.

Alvarenga, P., \& Piccinini, C. A. (2007). O impacto do temperamento, da responsividade e das práticas educativas maternas no desenvolvimento dos problemas de externalização e da competência social. Psicologia: Reflexão e Crítica, 20, 314-323.

Arsenio, W. F., \& Overton, W. F. (2004). Trajectories of physical aggression from toddlerhood to middle childhood: Predictors, correlates, and outcomes. Monographs of the Society for Research in Child Development, 69(4), 1-146.

Baumrind, D. (1971). Current patterns of parental authority. Developmental Psychology Monograph, 4(1, Pt. 2), 1-103.

Belsky, J., Woodworth, S., \& Crnic, K. (1996). Trouble in the second year: Three questions about family interaction. Child Development, 67, 556-578.

Campbell, S. B. (1995). Behavioral problems in preschool children: A review of recent research. Journal of Child Psychology and Psychiatry, 36, 113-149.

Capaldi, D., Chamberlain, P., \& Patterson, G. (1997). Ineffective discipline and conduct problems in males: Association, late adolescent outcomes and prevention. Agression and Violent Behavior, 2(4), 343-353.

Castro, R. E. F., Melo, M. H. S., \& Silvares, E. F. M. (2003). O julgamento de pares de crianças com dificuldades interativas após um modelo ampliado de intervenção. Psicologia: Reflexão e Crítica, 16(2), 309-318.

Crockenberg, S. B., \& Litman, C. (1990). Autonomy as competence in 2-year-olds: Maternal correlates of child defiance, compliance and self-assertion. Developmental Psychology, 26(6), 961-971.

DeBaryshe, B., Patterson, G., \& Capaldi, G. (1993). A performance model for academic achievement in early adolescent boys. Developmental Psychology, 29(5), 795-804.

Denham, S. A., Renwick, S. M., \& Holt, R. W. (1991). Working and playing together: Prediction of preschool social-emotional competence from mother-child interaction. Child Development, 62, 242-249.

Dumas, J. E., \& LaFreniere, P. J. (1993). Mother-child relationships as sources of support or stress: A comparision of competent, average, agressive, and anxious dyads. Child Development, 64, 1732-1754. 
Dumas, J., \& Wahler, R. G. (1985). Indiscriminate mothering as a contextual factor in agressive-oppositional child behavior: "Damned if you do damned if you don't". Journal of Abnormal Child Psychology, 13, 1-18.

Eddy, J. M., Leve, L. D., \& Fagot, B. I. (2001). Coercive family processes: A replication and extension of Patterson's coercion model. Agressive Behavior, 27, 14-25.

Egeland, B., Kalkoske, M., Gottesman, N., \& Erickson, M. F. (1990). Preschool behavior problems: Stability and factors accounting for change. Journal of Child Psychology and Psychiatry, 31, 891-909.

Ferreira, M. C. T., \& Marturano, E. M. (2002). Ambiente familiar e os problemas de comportamento apresentados por crianças com baixo desempenho escolar. Psicologia: Reflexão $e$ Crítica, 15(1), 35-44.

Grupo de Interação Social, Desenvolvimento e Psicopatologia. (2001). Observação da interação familiar - $30^{\circ}$ mês. Manuscrito não-publicado, Instituto de Psicologia, Universidade Federal do Rio Grande do Sul, Porto Alegre, RS.

Hart, C. H., Ladd, G. W., \& Burleson, B. R. (1990). Expectations of the outcomes of social strategies. Relations with socioeconomic status and maternal disciplinary styles. Child Development, 61, 127-137.

Hay, D. F. (1994). Prosocial development. Journal of Child Psychology and Psychiatry, 35, 29-72.

Keenan, K., \& Shaw, D. (1997). Developmental and social influences on young girls's early problem behavior. Psychological Bulletin, 121, 95-113.

Kliewer, W. (1991). Coping in middle childhood: Relations to competence, type A behavior, monitoring, blunting, and locus of control. Developmental Psychology, 27, 689-697.

Kochanska, G. (2002). Commited compliance, moral self, and internalization: A mediational model. Developmental Psychology, 38(3), 339-351.

Kuczynski, L., Kochanska, G., Radke-Yarrow, M., \& GirniusBrown, O. (1987). A developmental interpretation of young children's noncompliance. Developmental Psychology, 23, 799-806.

Landry, S. H., Smith, K. E., Swank, P. R., Assel, M. A., \& Vellet, S. (2001). Does early responsive parenting have a special importance for children's development or is consistency across early childhood necessary? Development Psychology, 37(3), 387-403.

Maccoby, E. E. (1966). The development of sex differences. Los Angeles: Stanford University Press.

McLoyd, V. C., \& Smith, J. (2002). Phisical discipline and behavior problems in african american, european, and spanic children: Emotional support as a moderator. Journal of Marriage and Family, 64, 40-53.

Oliveira, E. A., Frizzo, G. B., \& Marin, A. H. (2000). Atitudes maternas diferenciais para com meninos e meninas de 4 e 5 anos. Psicologia: Reflexão e Crítica, 13(3), 363-371.

Pacheco, J., Alvarenga, P., Reppold, C., Piccinini, C. A., \& Hutz, C. S. (2005). Estabilidade do comportamento anti-social na transição da infância para a adolescência: Uma perspectiva desenvolvimentista. Psicologia: Reflexão e Crítica, 18(1), 55-61.

Paley, B., Cox, M. J., \& Kanoy, K. W. (2001). The young family interaction coding system. In P. K. Kerig \& K. M. Lindahl (Eds.), Family observational coding systems: Resources for systemic research (pp. 273-288). Trenton, NJ: Lawrence Erlbaum.
Patterson, G. R., DeGarmo, D. S., \& Knutson, N. (2000). Hyperactive and antisocial behaviors: Comorbid or two points in the same process? Development and Psychopathology, 12, 91-106.

Patterson, G. R., Reid, J., \& Dishion, T. (1992). Antisocial boys. Eugene, OR: Castalia.

Pettit, G. S., Bates, J. E., Dodge, K. A., \& Meece, D. W. (1999). The impact of after-school peer contact on early adolescent externalizing problems is moderated by parental monitoring, perceived neighborhood safety, and prior adjustment. Child Development, 70, 768-778.

Piccinini, C. A., Tudge, J. R., Lopes, R. S., \& Sperb, T. M. (1998). Estudo longitudinal de Porto Alegre: Da gestação à escola. Manuscrito não-publicado, Instituto de Psicologia, Universidade Federal do Rio Grande do Sul, Porto Alegre, RS.

Silva, L. A. D. (1999). Determinantes psicossociais dos problemas de comportamento e do coeficiente intelectual (QI) de crianças pré-escolares. Dissertação de Mestrado nãopublicada, Instituto de Psicologia, Universidade Federal do Rio Grande do Sul, Porto Alegre, RS.

Simons, R. L., Simons, L. G., \& Wallace, L. E. (2004). Families, delinquency and crime. Linking society's most basic institution to anti-social behavior. Los Angeles: Roxbury.

Wangby, M., Bergman, L. R., \& Magnusson, D. (1999). Development of adjustment problems in girls: What syndromes emerge? Child Development, 70, 678-699.
Recebido: $11 / 04 / 2007$ $1^{a}$ revisão: $29 / 02 / 2008$ Aceite final: 16/04/2008 